\title{
Additive Technologies for Heat Transfer Enhancement
}

\author{
V.V. Cheverda ${ }^{1,2}$, K.S. Eloyan ${ }^{1}$, F.V. Ronshin ${ }^{1,2}$ \\ ${ }^{1}$ Kutateladze Institute of Thermophysics, SB RAS, Lavrentiev Prospect, \\ Novosibirsk, 630090, Russia \\ slava.cheverda@gmail.com \\ ${ }^{2}$ Novosibirsk State University, Pirogova Str. 2, Novosibirsk, 630090, Russia
}

In modern microprocessor the heat flux reaches about $200 \mathrm{~W} / \mathrm{cm}^{2}$. An air cooling system is not efficient for good performance of the microprocessor due to high temperature (close to $75^{\circ} \mathrm{C}$ ).

One promising method is to use thin liquid film driven by gas flow in the mini- and microchannel. Various studies show the effectiveness of the application of liquid film flow. It is experimentally demonstrated that the critical heat flux for a gasdriven liquid film moving along a surface with a smooth heater can exceed three times that of a liquid film freely flowing down the surface for the same fluid flow rate [1].

Additive technologies are widely used for aerospace industry, in medicine, in the car industry [2]. It is promising for the heat transfer processes intensification. To increase the efficiency of heat removal, it is proposed to use highly developed surfaces with microstructure to enhance the heat transfer processes.

The experimental setup has two circuits: liquid circuit and gas circuit. Liquid gear pump is used to pump the working fluid to the test cell. Ultrapure water is used as a working fluid. Dry nitrogen gas is supplied from gas bottle with pressure 200 bars and the gas flow rate is measured and regulated by the Bronkhorst mass flow meter and controller in a range of gas flow rates from 10 to $100 \mathrm{l} / \mathrm{min}$ is used. The two-phase flow is formed in a minichannel with a rectangular cross-section of $30 \mathrm{x} 0.9 \mathrm{~mm}^{2}$ and a length of $50 \mathrm{~mm}$. Heating element is produced from aluminum powder by EOS M 290 device. The surface of the produced element has periodic cylindrical vertical projections with a diameter and height of $400 \mu \mathrm{m}$, the distance between the centers of the projections is about $1 \mathrm{~mm}$. The schlieren method is used to visualize the processes inside the minichannel.

In the case of superficial gas velocity $0.018 \mathrm{~m} / \mathrm{s}$ and $0.026 \mathrm{~m} / \mathrm{s}$ the critical heat flux is about 70 and $101 \mathrm{~W} / \mathrm{cm}^{2}$, respectively in the range of superficial gas velocity between 7 and $12 \mathrm{~m} / \mathrm{s}$. Heat losses does not exceed $30 \%$ of the total heat that is released by the electrical heater.

The experiments were carried out at the expense of the grant of the Russian Foundation for Basic Research (agreement No. 18-48-543034)

\section{References}

[1] O. A. Kabov, V. Lyulin Yu, I. V. Marchuk, D. V. Zaitsev, "Locally heated shear-driven liquid films in microchannels and minichannels," Int. J. Heat Fluid Flow, vol. 28, pp. 103-112, 2007

[2] J. Davoud, W. W. Wits, "The utilization of selective laser melting technology on heat transfer devices for thermal energy conversion applications: A review," Renew. Sustain. Energy Rev., vol. 91, pp. 420-442, 2018. 